\title{
PEMANFAATAN DAN BENTUK PENGOLAHAN KULIT KAYU BERBASIS PENGETAHUAN LOKAL DAN IDENTITAS BUDAYA MASYARAKAT MAYBRAT
}

\section{(Utilization and Processing Type of Wooden Bark Based on Local Knowledge and Cultural Identity of Maybrat Community)}

\author{
Kosmas Assem ${ }^{1}$ Mariana Hermina Peday ${ }^{1 凶}$ dan Alexander Rumatora ${ }^{1}$ \\ Jurusan Kehutanan, Fakultas Kehutanan Universitas Papua Manokwari, Papua Barat, \\ 98314. Tlp/Fax: +62986211065. \\ ${ }^{\square}$ Penulis Korespondensi: Email: mariana.peday@yahoo.co.id \\ Diterima: 30 Jan 2018| Disetujui: 22 Feb 2018
}

\begin{abstract}
Abstrak
Penelitian ini bertujuan untuk mendeskripsikan informasi terkait pemanfaatan sumber daya hutan terutama komponen kulit vegetasi hutan untuk kebutuhan harian masyarakat melalui pengolahan kerajinan tangan di Kampung Ainot, Kabupten Maybrat. Untuk mendapatkan data, diskusi dan wawancara dilakukan dengan responden yang dipilih, sementara bentuk pengolahan dan teknis pengerjaannya diobservasi secara langsung di lapangan. Hasil penelitian memperlihatkan bahwa terdapat tiga jenis tumbuhan yang dimanfaatkan oleh masyarakat di Kampung Ainot antara lain: Gnetum gnemon L., Kleinhovia hospita dan Trichospermum sp. Selanjutnya dari jenis-jenis ini dianyam dan menghasilkan produk anyaman seperti noken ( $y u$ ), topi (way tau), koba (am) tanggu (seff) dan benang jahit. Sejauh ini belum ada upaya konservasi jenis-jenis tersebut dikarenakan jumlahnya yang masih cukup banyak dan intensitas pengambilannya yang masih rendah.

Kata kunci: Kult kayu, noken, produk anyaman, vegetasi hutan, Kabupaten Maybrat.

Abstract

This study has been focusing on describing information related to the use of natural resource in particular bark component from forest vegetation that intended for fulfilling daily need by way of handicraft desain and production in Ainot village of Maybrat district. In order to obtain data, discussion and semi-structural interview have been carried out with purposively selected respondents. While, types of production process of handicraft and its working mechanism were directly observed in the field from respondent. The result noticed that there was three species of forest vegetation that used by villagers for making handicraft such as: Gnetum gnemon L., Kleinhovia hospita dan Trichospermum sp. These species then processed to produce noken (yu), hat (way tau), head cover (am), waving net (seff), and sewing thread. So far, there was no effort to preserve and maintain the use of these forest vegetation species in order to keep it from distinction due to small intensity of exploitation.
\end{abstract}

Keywords: Wood bark, noken, woven product, forest vegetation, Maybrat district. 


\section{PENDAHULUAN}

Indonesia merupakan negara kepulauan yang memiliki kekayaan sumber daya alam, salah satunya adalah kekayaan sumber daya hutan (Renggi dkk. 2015). Hutan Indonesia merupakan hutan alam tropika basah yang memiliki kekayaan alam berupa keragaman flora dan fauna yang cukup tinggi. Sekitar 25.000-30.000 jenis (spesies) tumbuhan berbunga atau berbiji menghuni hutan alam Indonesia dan sekitar 4.000 jenis berupa pohon, yakni tumbuhan berkayu yang memiliki batang utama yang jelas terpisah dari tajuknya. Keragaman flora lainnya adalah lumut, ganggang, pakupakuan, epifit, palem, bambu dan tumbuhan bawah. Kekayaan tersebut disebabkan oleh biogeografi Indonesia yang membentang diantara 2 kawasan biogeorafi utama, yaitu Indomalaya dan Australasia (Sastrapradja dkk. 1989).

Hutan hujan tropis Papua merupakan hutan penyumbang keragaman tertinggi bagi kekayaan flora dan fauna Indonesia.Hutan ini memiliki formasi hutan hujan tropis Indomalaya yang kaya akan jenis, genera dan famili yang khas dan tidak dijumpai di daerah lain di Indonesia. Jumlah flora Papua diperkirakan terdapat $20.000-25.000$ jenis (Jhons 1997) dan 1.465 marga serta paling sedikit 142 marga bersifat endemik, dimana 90 - 250\% merupakan jenis endemik (De Fretes 2000). Tipe hutan Papua mengandung banyak jenis flora yang dapat dijadikan tanaman berguna bagi manusia. Namun sampai saat ini kekayaan flora tersebut belum diketahui dengan pasti, dikenal dan diketahui informasi botani, biologis dan penyebarannya (Lekitoo et al. 2017). Demikian pula pemanfaatan dalam rangka peningkatan kesejahteraan masyarakat masih dalam skala kecil dan bersifat tradisional. Tanpa mengenal jenis-jenis tumbuhan yang ada, kita tak mungkin mengetahui potensi, keanekaragaman maupun sifat-sifat lainnya (Petocz 1987).

Di Papua terdapat kurang lebih 312 suku dengan 251 bahasa (Asyaroh 2008) yang tersebar dan mendiami daratan Papua mulai dari batas pantai sampai dengan pengunungan. Keragaman tersebut menyebabkan cara hidup dari suku-suku di Papua berbeda - beda, seperti: bentuk ukiran-ukiran, tari-tarian, serta pemanfatan tumbuhan dalam budaya dan sistem sosial suatu kelompok masyarakat tertentu. Hal ini sangat dipengaruhi oleh perbedaan etnografi dan perbedaan fisiografi lingkungan dimana suku itu berada (Boelars 1992).

Masyarakat Papua dalam menunjang kehidupan sehari-hari telah memanfaatkan tumbuhan untuk berbagai keperluan sejak dahulu kala. Hal ini dapat dilihat dari beberapa produk lokal seperti bangunan rumah, bahan pangan, obat obatan tradisional, noken/tas, dan lainlain yang digunakan oleh suku-suku di Papua.

Suku Maybrat adalah salah satu suku di Papua yang mendiami daerah kepala burung Papua. Dalam mencukupi kebutuhan hidupnya sehari-hari, masyarakat memanfaatkan tumbuhan yang ada disekitarnya. Arne (2011) melaporkan bahwa masyarakat Suku Maybrat di Distrik Ayamaru Utara Kabupaten Maybrat memanfaatkan 7 spesies tumbuhan hutan dari 6 famili sebagai bahan baku pembangunan rumah. Korain (2013) melaporkan Masyarakat Maybrat di Kampung Sire Distrik Mare Selatan memanfaatkan sebanyak 27 jenis kulit kayu sebagai obat-obatan 
tradisional, 13 jenis tumbuhan sebagai bahan pembungkus makanan, 8 jenis tumbuhan sebagai bahan penerangan, 7 jenistumbuhan sebagai bahan pembangunan rumah, 7 jenis tumbuhan sebagai bahan ramuan minuman lokal dan 3 jenis tumbuhan sebagai bahan pembuatan noken

Penelitian ini bertujuan untuk mengetahui jenis tumbuhan yang diambil kulitnya sebagai bahan baku kerajinan tangan oleh masyarakat Kampung Ainot Distrik Aifat Kabupaten Maybrat. Selain itu juga untuk mengetahui bentuk pemanfaat tumbuhan sebagai bahan baku kerajinan tangan oleh masyarakat Kampung Ainot Distrik Aifat Kabupaten Maybrat.

\section{METODE PENELITIAN}

Penelitian ini dilaksanankan di Kampung Ainot Distrik Aifat Kabupaten Maybrat selama 1 bulan yakni Juni hingga Juli 2017. Subjek penelitian ini adalah masyarakat Kampung Ainot yang memanfaatkan kulit kayu sebagai bahan kerajinan tangan dan melihat jenis tumbuhan yang kulitnya sebagai bahan baku kerajinan. Metode yang digunakan dalam penelitian ini adalah metode deskritif dengan teknik observasi lapangan dan wawancara semi structural.

\section{Variabel Penelitian}

Penelitian ini terdiri dari variable utama dan variable penunjang. Variabel utama yang diamati antara lain: jenis tumbuhan yang mana tumbuhan tersbut bagian kulitnya dimanfaatkan sebagai bahan kerajinan tangan oleh masyarakat serta bentuk pemanfaatan kulit kayu tersebut sebagai bahan kerajinan tangan. Sementara variabel penunjang yang diamati meliputi: pola konservasi jenis yang dilakukan oleh masyarakat dan pola transfer pengetahuan masyarakat dalam memanfaatkan kulit kayu sebagai bahan baku kerajinan tangan.

\section{Pelaksanaan Penelitian}

\section{Penentuan responden}

Responden terdiri dari responden kunci dan responden umum. Responden kunci ditentukan secara sengaja yaitu Kepala Kampung, Tua Adat, Tokoh Masyarakat. Sedangkan responden umum ditentukan dengan menggunakan metode snowball, terhadap masyarakat yang mengetahui dan memanfaatkan tumbuhan sebagai bahan baku kerajinan. Jumlah responden umum yang digunakan dalam penelitian ini adalah 5 orang dan responden kunci 6 orang sehingga jumlah keseluruhan responden adalah 11 orang.

\section{Pengumpulan Data}

Data yang dikumpulkan dari masyarakat terdiri dari data primer dan data sekunder. Data primer yang dikumpulkan, antara lain: jenis tumbuhan yang bagian kulitnya dimanfaatkan sebagai bahan kerajinan tangan yang antara lain berupa: nama jenis, nama lokal, nama ilmiah, serta famili dari jenis tersebut. Kemudian bentuk pemanfaatan kulit kayu tersebut sebagai bahan kerajinan tangan dengan data yang dikumpulkan meliputi: proses pemanfaatan kulit kayu, cara pengambilan kulit kayu, cara pengolahan bahan baku, cara penganyamannya, bentuk - bentuk kerajinan tangan yang dihasilkan serta nilai ekonomi dari hasil kerajinan tangan

Data sekunder yang dikumpulkan, antara lain: pola konservasi tradisional yang dilakukan oleh masyarakat terhadap kelestarian jenis yang dimanfaatkan 
sebagai bahan baku kerajinan. Pola transfer pengetahuan masyarakat dalam memanfaatkan kulit kayu sebagai bahan baku kerajinan tangan serta keadaan umum lokasi penelitian.

\section{Analisa Data}

Analisa data dilakukan dengan cara deskriptif dan ditampilkan dalam bentuk tabel dan gambar.

\section{HASIL DAN PEMBAHASAN}

\section{Jenis Tumbuhan}

Jenis-jenis tumbuhan yang dimanfaatakan kulit kayunya sebagai bahan baku anyaman kerajinan tangan oleh masyarakat tersaji pada Tabel 1 . Tabel 1 menunjukkan bahwa masyarakat Maybrat memanfaatkan kulit kayu dari tiga jenis tumbuhan yang tergolong dalam dua famili untuk dijadikan sebagai bahan baku anyaman kerajinan tangan. Jenisjenis tumbuhan tersebut merupakan jenisjenis vegetasi hutan sekunder dan primer. Gnetumgnemon L. merupakan jenis yang seringkali ditemukan masyarakat pada hutan sekuder maupun hutan primer, sedangkan jenis Kleinhovia hospita dan Trichospermum sp. dapat ditemukan masyarakat pada areal bekas kebun. Kedua jenis tersebut merupakan jenis tumbuhan pionir atau tumbuhan berkayu yang tumbuh pertama pada suksesi setelah tumbuhan semak. Keduanya merupakan tanaman cepat tumbuh (fast growing species). Jenis- jenis kulit kayu yang digunakan dapat dilihat pada Gambar 1.

Tabel 1. Jenis tumbuhan yang dimanfaatkan oleh masyarakat Kampung Ainot sebagai bahan baku anyaman kerajinan tangan.

\begin{tabular}{|c|c|c|c|c|c|c|}
\hline \multirow[t]{2}{*}{ No. } & \multicolumn{2}{|l|}{ Nama Jenis } & \multirow[t]{2}{*}{ Famili } & \multirow{2}{*}{$\begin{array}{c}\text { Tipe } \\
\text { Tumbuhan }\end{array}$} & \multirow{2}{*}{$\begin{array}{c}\text { Lokasi } \\
\text { Pengambilan }\end{array}$} & \multirow{2}{*}{$\begin{array}{c}\text { Bentuk } \\
\text { Pemanfaatan }\end{array}$} \\
\hline & Ilmiah & Lokal & & & & \\
\hline 1. & Gnetum gnemon & Ftuoh & Gnetaceae & Pohon & $\begin{array}{l}\text { Hutan } \\
\text { primer }\end{array}$ & $\begin{array}{l}\text { Tanggul } \\
\text { ikan }\end{array}$ \\
\hline 2. & Kleinhovia hospita & Yufa & Timiliaceae & Pohon & $\begin{array}{l}\text { Bekas } \\
\text { kebun }\end{array}$ & $\begin{array}{l}\text { Noken, topi dan benang } \\
\text { untuk menjahit koba } \\
\text { atau payung tradisional }\end{array}$ \\
\hline 3. & Trichospermum sp. & Pyek & Timiliaceae & Pohon & $\begin{array}{l}\text { Bekas } \\
\text { kebun }\end{array}$ & $\begin{array}{l}\text { Noken, topi dan benang } \\
\text { untuk menjahit koba } \\
\text { atau payung tradisional }\end{array}$ \\
\hline
\end{tabular}

Nauw (2016) mengungkapkan bahwa masyarakat suku Maybrat di Kampung Kambuaya Distrik Ayamaru Timur memanfaatkan pohon atau kulit kayu sebanyak tiga jenis sebagai bahan pembuatan noken yaitu Mictromisa sp. Trichospermum sp.dan Gnetumgnemon L. Masyarakat Kampung Kambuaya menyebutkan noken dengan bahasa Maybrat yaitu $Y u$. 


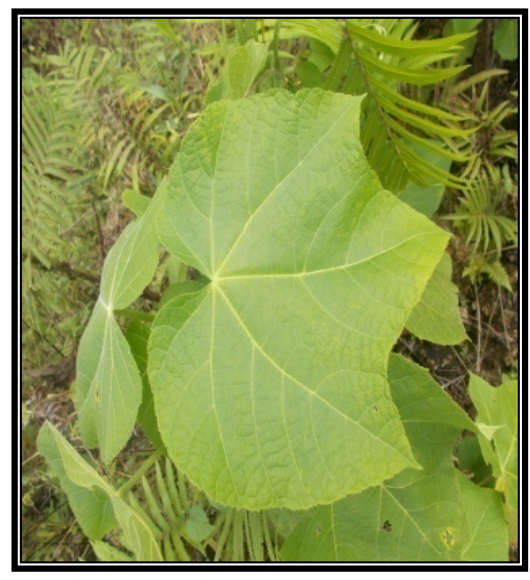

a. Kleinhovia hospita

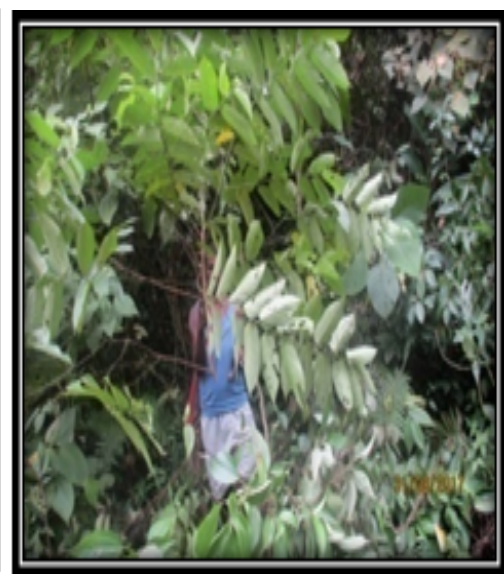

b. Trichospermum sp.

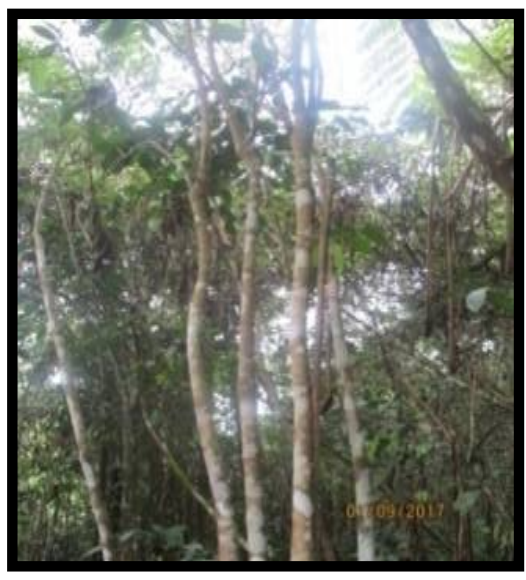

c. Gnetum gnemon L.

Gambar 1. Jenis-Jenis tumbuhan bahan baku kulit kayu untuk anyaman kerajinan tangan yang dimanfaatakan oleh masyarakat Kampung Ainot.

\section{Bentuk Pemanfaatan Kulit Kayu Sebagai Bahan Kerajinan}

\section{Cara pengambilan kulit kayu}

Cara pengambilan kulit kayu dari ketiga jenis tumbuhan yang dimanfaatkan sebagai bahan baku anyaman kerajinan tangan dimulai dengan menentukan bentuk kerajinan tangan apa yang akan dibuat, pencarian pohon bahan baku, penebangan, pemisahan serat kulit, dan pengikisan kambium. Bila masyarakat ingin membuat tanggul (jaring penangkap ikan) maka jenis pohon yang dicari adalah Gnetum gnemon L., sedangkan bila masyarakat ingin membuat topi, noken, dan benang jahit koba (payung tradisional) maka jenis pohon yang dicari adalah Kleinhovia hospita dan Trichospermum sp. Lokasi pengambilan bahan baku untuk ke tiga jenis tersebut hampir sama yaitu bekas kebun ataupun hutan sekunder untuk jenis Gnetumgnemon L. juga dicari pada hutan primer. Jarak tempuh dari kampung ke hutan sekunder atau bekas kebun \pm 1 - 2 $\mathrm{km}$, sedangkan jarak tempuh ke areal hutan primer $\pm 2 \mathrm{~km}$.

Dalam proses pemanfaatan kulit kayu untuk anyaman kerajinan tangan berupa noken membutuhkan kulit kayu yang cukup banyak, biasanya diambil dari 5 pohon atau lebih, sedangkan untuk membuat topi membutuhkan bahan baku dari 3 pohon. Sementara untuk menganyam tanggul membutuhkan bahan baku yang berasal dari lima pohon atau lebih, dan untuk menjahit koba cukup bahan baku diambil dari 1 pohon saja.

Alat yang digunakan masyarakat untuk mengambil bahan baku yaitu parang dan pisau. Parang digunakan untuk membersihkan jalan dari rumput, semak dan untuk menebang bahan baku serta mengupas kulit bahan baku. Sedangkan pisau digunakan untuk mengupas serat dari kulit dan mengikis atau mengeluarkan kambium dari serat.

Setelah menemukan pohon yang diinginkan, masyarakat selanjutnya menebang pohon tersebut dengan cara 
membersihkan semak dan rumput disekitar pohon kemudian melakukan penebangan dengan cara memotong setinggi $30 \mathrm{~cm}$ dari permukaan tanah karena alasan kulit bahwa bagian kulit yang mendekati perakaran cenderung keras dan tidak layak untuk keperluan menganyam. Setelah memisahkan bagian atas batang, biasanya ukuran panjang batang yang diambil $\pm 1-2 \mathrm{~m}$ supaya panjang serat yang diperoleh juga berukuran panjang seperti itu. Selanjutnya setelah rebah bagian batang atas pohon dipotong pada posisi di bawah percabangan dengan alasan bahwa jika dipotong bagian atas maka saat pengupasan serat akan rusak. Kemudian

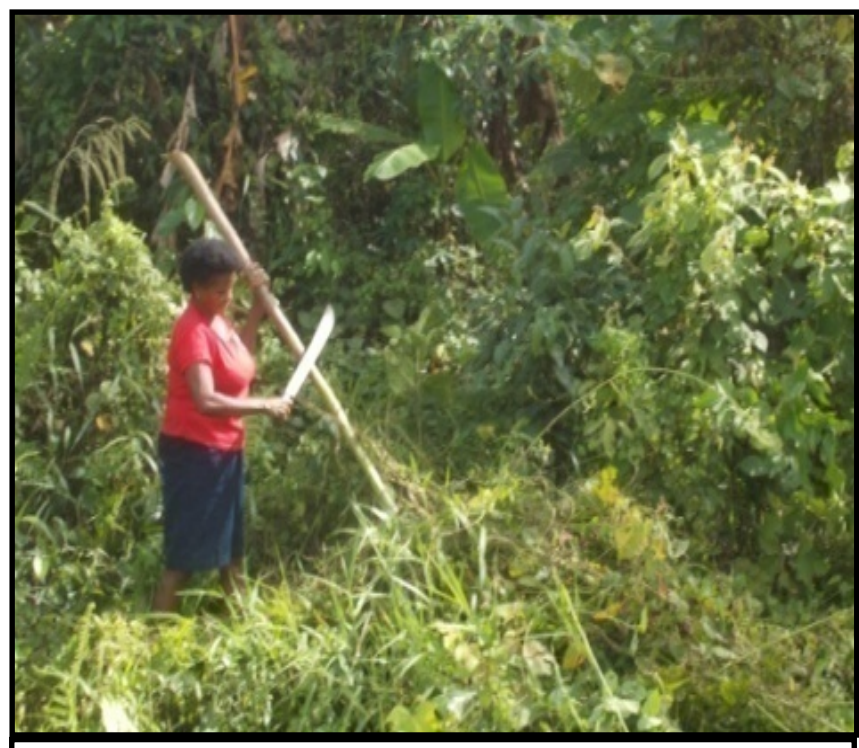

a).Menebang pohon dengan mengunakan parang bagian batang pohon tengah yang diambil lalu dibelah menjadi dua bagian supaya pada saat kulitnya dikupas dari pohon serat tetap merata atau tidak rusak. Selanjutnya untuk memisahkan kulit dari batang, maka bagian batang dalam dipatah atau ditarik sehingga terpisah dari kulit. Setelah itu,bagian kulit luar pisahkan dari kulit bagian dalam atau serat dengan menggunakan pisau, lalu serat tersebut dibersihkan daricairan kambium yang masih menempel pada serat melalui pengikisan dengan pisau berkali-kali sampai bersih agar serat mudah untuk dikeringkan dan tetap awet, seperti terlihat pada Gambar 2.

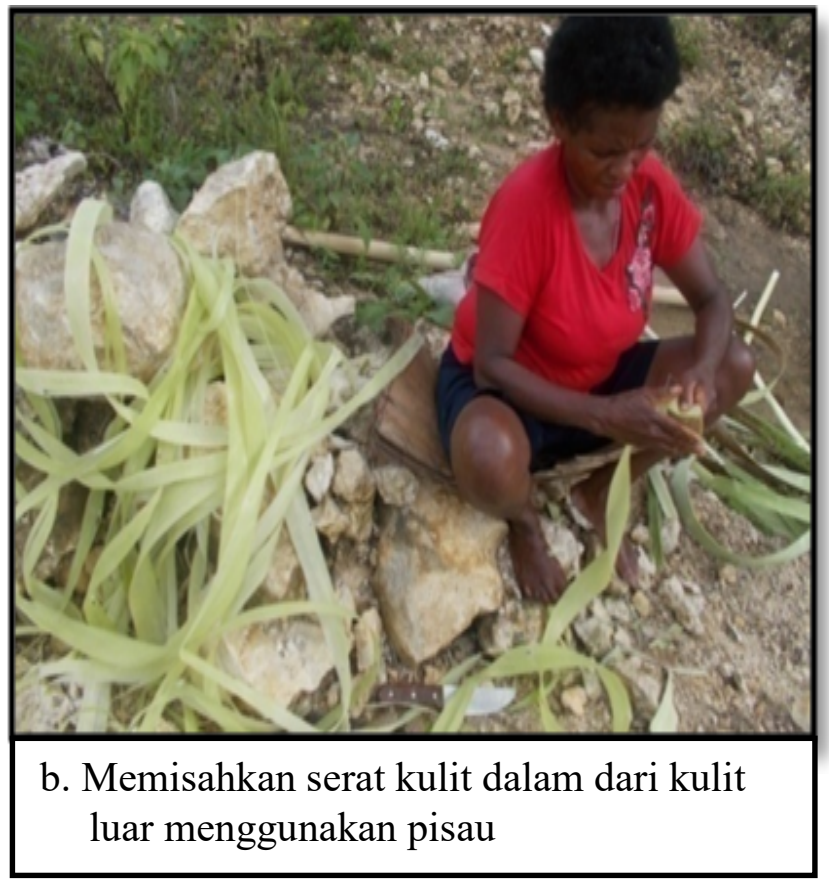

Gambar 2. Cara pengambilan bahan baku; a). menebang pohon deng mengunakan parang, b). memisahkan serat kulit dalam dari kulit luar menggunakan pisau.

Kriteria yang digunakan dalam pengambilan bahan baku

Kriteria yang dipakai masyarakat dalam pengambilan kulit kayu yang akan

dijadikan bahan baku kerajinan yaitu diameter, tinggi, tebal kulit dan warna kulit. 
Tabel 2. Kriteria dan ukuran yang dipakai dalam pengambilan bahan baku oleh masyarakat Kampung Ainot.

\begin{tabular}{lllllllll}
\hline No. & Nama Jenis & \multicolumn{3}{l}{$\begin{array}{l}\text { Ukuran } \\
\text { Pohon }\end{array}$} & \multicolumn{3}{l}{ Ukuran Kulit Kayu } & \multicolumn{2}{l}{ Warna Kulit } \\
\cline { 3 - 8 } & & $\begin{array}{l}\varnothing \\
(\mathrm{cm})\end{array}$ & $\begin{array}{l}\text { Pjg } \\
(\mathrm{m})\end{array}$ & $\begin{array}{l}\text { Pjg } \\
(\mathrm{m})\end{array}$ & $\begin{array}{l}\text { Lbr } \\
(\mathrm{cm})\end{array}$ & $\begin{array}{l}\text { Tbal } \\
(\mathrm{cm})\end{array}$ & Luar & Dalam \\
\hline 1 & Gnetum gnemon L & $3-9$ & $1-7$ & $1-3$ & $1-7$ & 0,6 & Coklat & Putih \\
2 & Trichospermum sp & $3-8$ & $1-3$ & $1-3$ & $1-7$ & 0,6 & Putih & Putih \\
3 & Kleinhovia hospita & $3-8$ & $1-5$ & $1-3$ & $1-7$ & 0,7 & Hijau & Putih \\
\hline
\end{tabular}

Ket.=Ø: diameter; Tgi: tinggi ; Pjg: panjang ; Lbr: Lebar ; Tbal: tebal.

Tabel 2 menunjukkan bahwa pohon yang akan dijadikan sebagai bahan baku memiliki tinggi berkisar 1-7 $\mathrm{m}$ dengan diameter 3-9 cm, warna kulit luar coklat, putih dan hijau. Masyarakat mengambil tumbuhan dengan diameter berkisar antara 3-9 cm untuk bahan baku anyaman dan kerajinan tangan karena memiliki serat sangat lunak. Sedangkan untuk tumbuhandengan diameter kurang dari tiga $\mathrm{cm}$ seratnya mudah putus dan lebih dari $9 \mathrm{~cm}$ serat sudah tua sangat keras dan mudah putus. Ukuran kulit kayu yang dipakai dalam pengambilan bahan baku antara lain panjang 1-3 m, lebar 1-7 cm dan tebal kulit 0,6-0,7 cm.

\section{Cara Pengolahan, Penganyaman dan Bentuk Hasil Kerajinan}

Masyarakat suku Maybrat, sub suku Aifat Kampung Ainot hanya memanfaatkan serat kulit kayu dari dua jenis pohon, yaitu Kleinhovia hospita dan Trichospermum sp. untuk dijadikan bahan baku pembuatan noken, tanggul, topi tradisional dan benang jahit payung tradisional. Bahan baku tersebut diperoleh dari areal bekas kebun ataupun hutan sekunder. Proses pengambilan bahan baku dapat dilakukan dengan cara menebang pohonnya, lalau mengupas kulitnya, lalu mengupas kulitnya, selanjutnya bagian serat yang digunakan diambil dengan mengupas atau memisahkan kulit dari kulit luar. Kemudian dari serat kulit bagian dalam tersebut dikeluarkan kambium yang masih menenmpel dengan mengikisnya sampai bersih. Hal ini juga dilakukan oleh masyarakat suku Yali di Kampung Hubakma pada kulit kayu yang diambil untuk membuat noken (Walianggen dan Rumatora 2016). Proses selanjutnya yaitu penjemuran dan pengeringan serat sampai serat tersebut benar-benar kering baru kemudian dapat dianyam. Seluruh kegiatan kerajinan tangan tersebut hanya dilakukan oleh kaum perempuan baik kaum muda maupun tua. Namun saat ini kegiatan kerajinan tersebut hanya dilakukan oleh para orang tua perempuan.

\section{Noken}

Proses penganyaman noken dimulai dengan menganyam bagian dasar noken,ccaranya dengan menempatan benang lalu dianyam bersilangan sambil diberi warna yang diinginkan dengan bahan pewarna wantex (sintetis). Pada zaman dahulu, bahan pewarna yang digunakan untuk memberi warna pada anyaman noken yaitu pewarna alami yang 
berasal dari tumbuhan dan proses untuk mengola tumbuhn menjadi bahan pewarna sangat rumit sehingga pengrajin dapat memanfaatkan sintetis karena prosesnya sangat mudah. Proses penganyaman dilanjutkan pada bagian samping noken mengelilingi atau memutar bagian bawah atau dasar noken, dan kemudian bagian terakhir dari proses pembuatan noken adalah membuat tali noken. Pada waktu lampau tali noken terbuat dari serat kulit pohon Gnetum gnemon yang dianyam, namun pada saat ini tali noken telah dimodifikasi dengan dibuat (dijahit) menggunakan dari bahan kain yang warnanya sesuai keinginan pengrajin. Maksud dari pembuatan tali noken agar mudah dipakaikan pada bagian kepala atau bahu sipemakai. Biasanya untuk noken berukuran besar dipakaikan pada kepala, sedangkan noken berukuran kecil dipakaikan dibagian bahu. Ukuran noken menurut masyarakat Maybrat di Kampung Ainot, yaitu jika lebar noken berukuran $\pm 50 \mathrm{~cm}$, maka noken tersebut disebut noken besar, sedangkan jika noken berukuran $\pm 30 \mathrm{~cm}$ disebut sebagai noken kecil.

Noken dalam bahasa daerah Maybrat disebut ' $y u$ ' dengan ukuran bervariasi. Noken besar biasanya dipakai sebagai alat untuk menampung hasil kebun atau hasil tani,juga digunakan sebagai kantong menyimpan pakaian, dan digunakan dalam setiap melalukan tarian adat oleh masyarakat di kampung Ainot ataupun oleh masyarakat Maybrat secara keseluruhan. Sedangkan untuk noken berukuran kecil biasanya digunakan masyarakat kampung Ainot sebagai tas buku untuk anak bersekolah dan tas kantong peralatan ibadah.

Topi
Proses pengambilan bahan baku dengan cara menebang bahan baku, proses pengolahan bahan baku untuk menganyam topi hampir sama seperti noken, sedangkan cara menganyam topi dilakukan dengan cara menyam bagian kerucut terlebih dahulu kemudian menganyam bagian samping hingga menjadi topi. Topi dalam bahasa Maybrat disebut 'way tau'. Topi tradisional ini hanya digunakan pada saat acara adat seperti penyambutan tamu dan peminangan.

\section{Tanggu}

Alat tanggu atau jaring penangkap ikan terbuat dari kulit pohon Gnetum gnemon. Cara pengambilan kulit kayu dan cara pengolahan hampir sama seperti noken, topi dan koba. Proses penganyaman dilakukan dengan cara menggunakan serat yang sudah dikeringkan lalu dibelah menjadi serat panjang berukuran lebar $\pm 3 \mathrm{~mm}$, kemudian menempatkan serat 3 benang serat diatas paha lalu digulung berbentuk dan membentuk benang woll. Proses selanjutnya yaitu menganyam bagian dasar dan selanjutnya menganyam bagian keliling melingkar dan menjadi tanggu lalu dibuat tempat pegangan untuk menangkap ikan dengan menggunakan rotan (Callamus spp.) yang berukuran sedang dengan ukuran diameter $2 \mathrm{~cm}$.

\section{Benang jahit}

Pemanfaatan serat kulit pohon Kleinhovia hospita dan Trichospermum sp. sebagai benang untuk menjahit koba. Proses untuk menjahit koba dapat dilakukan dengan cara memasukan benang ke dalam lobang jarum kemudian menjahit dengandan selanjutnya menja payung tradisional. 
Jenis kerajinan tangan yang dihasilkan oleh ibu-ibu kampung Ainot berasal dari jenis pohon Kleinhovia hospita, Trichospermum sp. dan Gnetum
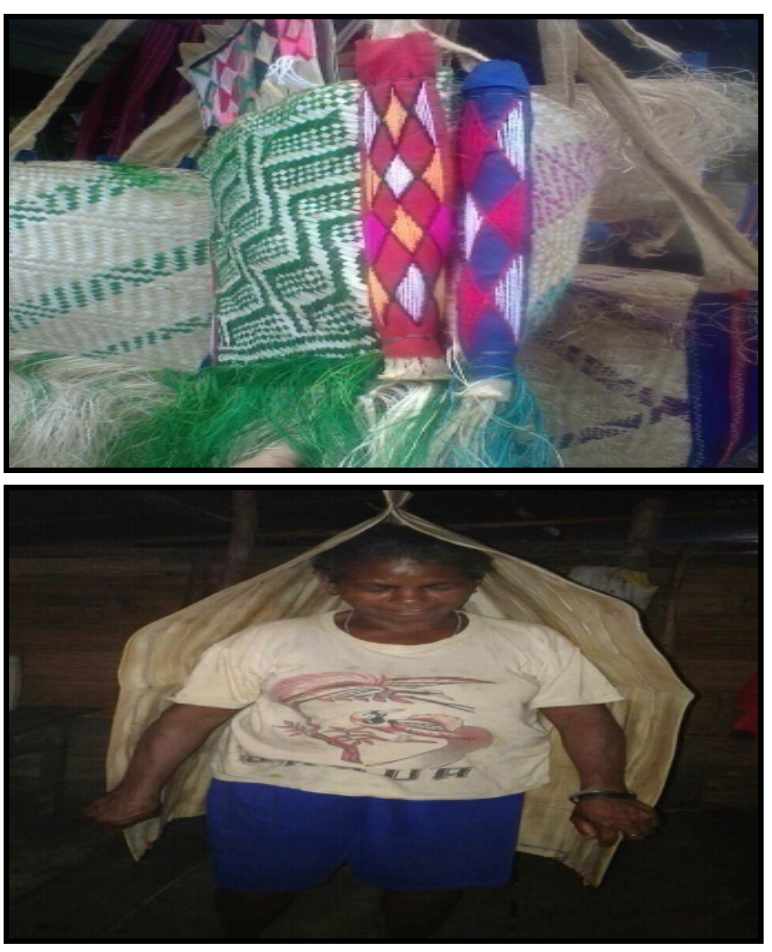

gnemon. Kerajinan tangan yang dihasilkan adalah noken $(y u)$, topi (way tau), koba (am) dan tanggu (seff) dapat dilihat pada Gambar 3.
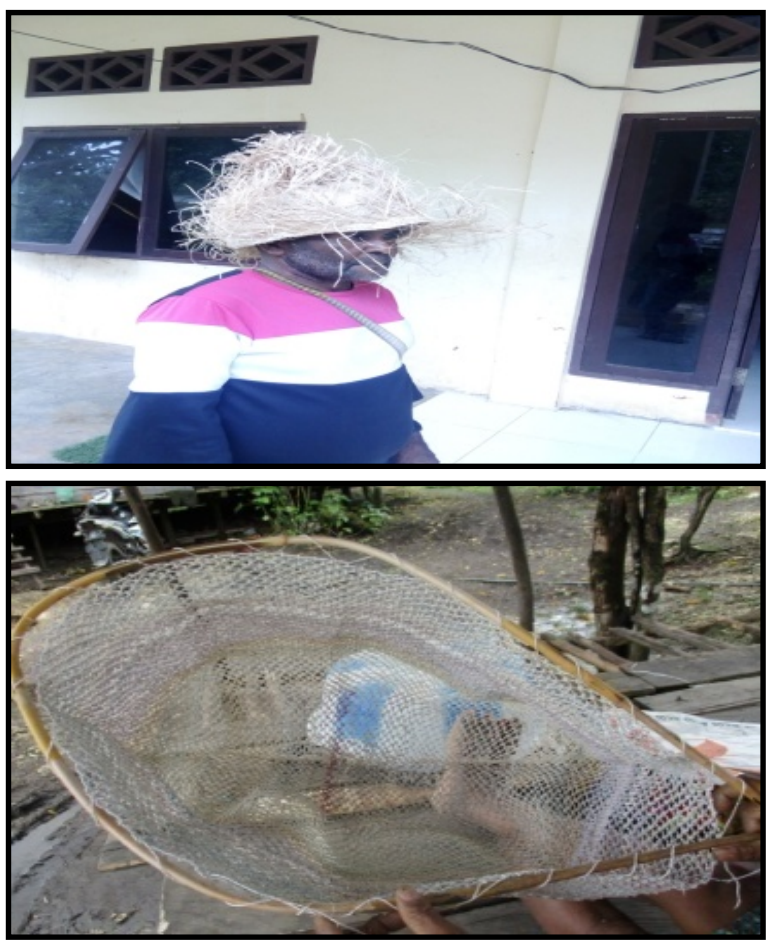

Gambar 3. Bentuk hasil kerajinan masyarakat Ainot yang terdiri dari noken, topi, koba dan tanggu.

\section{Nilai Ekonomi}

Hasil kerajinan tangan masyarakat di kampung Ainot, sebagian dipakai sendiri dan sebagian dijual untuk memenuhi kebutuhan rumah tangga. Nilai jual dari masing - masing hasil kerajinan tangan masyarakat kampung Ainot, cukup bervariasi yaitu dari Rp. 100.000 hingga Rp. 200.000 tergantung ukurannya. Topi tradisional berada pada kisaran harga Rp. 50.000, payung tradisional berkisar antara Rp. 50.000 - 100.000 tergantung ukuran dan rata-rata tanggu dijual dengan harga Rp. 100.000.

\section{Konservasi Jenis}

Berdasarkan hasil wawancara bahwa masyarakat di kampung Ainot tidak melakukan upaya konservasi terhadap jenis-jenis tumbuhan yang dijadikan sebagai bahan baku kerajinan tangan. Hal ini disebabkan jenis - jenis tersebut jumlahnya masih banyak dan dapat tumbuh secara alami kemudian tumbuhan ini dipandang masyarakat sebagai tumbuhan pionir yang bersama semak dan rumput pada areal bekas kebun sehingga untuk saat ini kebutuhan bahan baku masih sangat cukup dan tidak perlu dilakukan upaya konservasi terhadap jenis-jenis tersebut. 


\section{Pola Transfer Pengetahuan}

Pengetahuan masyarakat tentang pemanfaatan kulit kayu sebagai bahan baku kerajinan merupakan budaya yang diwariskan secara turun-temurun dari orang tua perempuan kepada anak-anak. Pola transfer pengetahuan yang dianut oleh masyarakat kampung Ainot dalam pemanfaatan kulit kayu sebagai bahan baku kerajinan adalah sistem terbuka sehingga pengetahuan tersebut dapat diketahui oleh semua orang, baik kaum perempuan, kaum laki-laki tanpa mengenal umur. Sistem transfer pengetahuan masyarakat kampung Ainot dalam pemanfaatan kulit kayu sebagai bahan baku kerajinan dilakukan melalui beberapa cara, antara lain: dengan menunjukkan langsung jenis tumbuhan yang dimanfaatkan sebagai bahan baku kerajinan pada saat di hutan dan kebun. Sedangkan teknik pengelolaan bahan baku dan proses penganyaman diajarkan langsung oleh orang tua kepada anakanak. Untuk saat ini pengetahuan masyarakat tentang pemanfaatan kulit kayu sebagai bahan baku kerajinan kurang diminati oleh generasi muda.

\section{DAFTAR PUSTAKA}

Arne S. 2011. Jenis-jenis kulit yang dimanfaatkan oleh masyrakat Ayamaru Utara sebagai bahan pembangunan rumah di Kabupaten Maybrat. Skripsi Sarjana Kehutanan Universitas Negeri Papua Manokwari. (tidak diterbitkan).

Asyaroh IH. 2008. Ensiklopedia anak nusantara Papua. (catatan pertama). Pustaka Angin Mamiri. Surabaya.

Boelars J. 1992. Manusia Irian dahulu, sekarang, masa depan. Gramedia Pustaka Utama. Jakarta
De Fretes Y. 2000. Laporan Rapid Assessment Program (RAP) CI-IP dan Uncen di Yongsu, Jayapura. Conservation International-Indonesian Program. Jayapura. Tidak dipublikasikan.

John R. 1997. Common forest trees of Irian Jaya Papua - Indonesia. Royal Botanical Garden, Kew. Inggris.

Korain A. 2013 Jenis-jenis kulit kayu dan pemanfaatannya dalam Suku Maybrat di Kampung Sire Distrik Mare Selatan Kabupaten Maybrat. Skripsi Sarjana Kehutanan Universitas Negeri Papua Manokwari. (tidak diterbitkan).

Lekitoo K, Peday HFZ, Panambe N and Cabuy RL. 2017. Ecological and ethnobotanical facet of 'Kelapa Hutan' (Pandanus spp.) and perspectives towards its existence and benefit. International Journal of Botany, 13: 103-114.

Nauw A. 2016. Kulit kayu sebagai bahan baku anyaman noken dalam kehidupan masyarakat Kampung Kambuaya Distrik Ayamaru Timur Kabupaten Maybrat. Skripsi Sarjana Kehutanan, Fakultas Kehutanan, Universitas Papua. Manokwari. (Tidak diterbitkan).

Petocz RG. 1987. Konservasi alam dan pembangunan di Irian Jaya. Jakarta Grafitipers.

Renggi ER, Indra $M$, MuslichM dan Asmui. 2015. Pengelolaan sumber daya hutan dan pemanfaatn mekanisme pembayaran layanan ekosistem di hutan adat. Buku Panduan, Aliansi Manyarakat Adat Nusantara dan Japan Social Development Fund.

Sastrapradja DS, Adisoemarto K, Kartawinata S, Sastrapradja dan M.A Rifai. 1989. Keanekaragaman hayati 
untuk kelangsungan hidup bangsa. Puslitbang Bioteknologi - LIPI. Bogor.

Walianggen Y dan Rumatora A. 2016. Rekonstruksi etnoteknologi noken kulit pohon oleh suku Yali di Kampung Hubakma Kabupaten Yalimo. Jurnal Kehutanan Papuasia, 2 (1): $17-23$. 